\title{
Appendix 2:
}

- Centre for Reviews and Dissemination databases: NHS EED and HTA

https://www.crd.york.ac.uk/CRDWeb/

- Tufts Cost-effectiveness Analysis Registry (former Harvard Cost-Effectiveness Analysis database)

http://healtheconomics.tuftsmedicalcenter.org/cear4/Home.aspx

- $\quad$ Nice Decision Support Unit

http://nicedsu.org.uk/

- $\quad$ CADTH

https://www.cadth.ca

- ISOQOL

http://www.isoqol.org/

- Eunethta

https://www.eunethta.eu/

- ISPOR

https://www.ispor.org/ 